\title{
\begin{tabular}{|l|l|l|l|l|}
\hline $\mathrm{M}$ & $\mathrm{R}$ & $\mathrm{S}$ & Internet Journal of & Nitride Semiconductor Research \\
\hline
\end{tabular}
}

Volume 1, Article 35

\section{Optical Properties of Nitride-based Structures Grown on 6H-SiC}

\author{
D.V. Tsvetkov, A.S. Zubrilov \\ Cree Research EED \\ and \\ loffe Physical-Technical Institute \\ V. I. Nikolaev, V.A. Soloviev, V.A. Dmitriev \\ loffe Physical-Technical Institute
}

This article was received on May 31, 1996 and accepted on November 12, 1996.

\begin{abstract}
The luminescent properties of AIGaN epitaxial layers with AIN mole fractions up to $30 \%$ and various types of AIGaN/GaN-based heterostructures have been studied. The structures were grown on $6 \mathrm{H}$-SiC substrates by MOCVD. The structures' cathodoluminescence and electroluminescence were measured. A "blue" shift of the edge luminescent peak position for AIGaN alloys was measured to be a non-linear function on the AIN mole fraction. For $p-A I G a N / n-G a N$ double heterostructures $(\mathrm{DH})$, the edge peak position was detected at 365 $\mathrm{nm}(300 \mathrm{~K})$. For a p-Al $0.05 \mathrm{Ga}_{0.95} \mathrm{~N} / \mathrm{n}-\mathrm{Al}_{0.03} \mathrm{Ga}_{0.97} \mathrm{~N}$ heterostructure, the electroluminescent edge peak was observed at $355 \mathrm{~nm}(300 \mathrm{~K})$. The effects of temperature and forward current on the edge electroluminescence of theAIGaN/GaN DH's were investigated.
\end{abstract}

\section{Introduction}

GaN and GaN-based alloys (AIGaN and InGaN) are attractive materials for the fabrication of blue and ultraviolet light emitting diodes and laser diodes due to their large direct band gap (1.9 eV for InN, 3.4eV for GaN, $6.2 \mathrm{eV}$ for AIN) [1]. Previously, we reported the first GaN homojunctions and AIGaN/GaN heterojunctions [2] which had an edge electroluminescence (EL) peak situated at $365 \mathrm{~nm}(300 \mathrm{~K})$. In this paper, we report on the optical properties of AIGaN solid solutions with AIN mole fractions in the range $0-30 \%$ and AIGaN/GaN pn structures grown on $6 \mathrm{H}-\mathrm{SiC}$ substrates by metalorganic chemical vapor deposition (MOCVD).

\section{Experimental Procedure}

AlGaN undoped epitaxial layers about $0.8 \mu \mathrm{m}$ thick and $\mathrm{AlGaN} / \mathrm{GaN}$ pn structures were on standard $30 \mathrm{~mm} 6 \mathrm{H}-\mathrm{SiC}$ wafers by MOCVD [3]. Epitaxial layers had smooth mirror-like surfaces. The crystal structure of the layers was described in [4]. Mg and Si dopants were used for $\mathrm{p}$ - and n-layers, respectively, to control the carrier concentrations in the range from $\sim 1 \times 10^{16}$ to $\sim 1 \times 10^{19} \mathrm{~cm}^{-3}$. Carrier concentration was measured by mercury probe. Two types of structures were investigated: $\mathrm{p}$ - AIGaN/n-AIGaN heterostructures and p-AIGaN/GaN/n-AIGaN double heterostructures (DH). The AIGaN layers had AIN mole fractions up to $30 \%$. The AIGaN alloys used in the heterostructures had AIN mole fractions up to $10 \%$. The epitaxial layers and structures were characterized by cathodoluminescence $(\mathrm{CL})$ and $\mathrm{EL}$ in the temperature range from $200-400 \mathrm{~K}$. While measuring, we eliminate the spectral sensitivity of our setup. For $\mathrm{CL}$, excitation with a $4-15 \mathrm{keV}$ electron beam was used. In AIGaN heterostructures, mesas $300 \mathrm{~mm}$ in diameter were formed by reactive ion etching [5]. In AIGaN/GaN DHs, $20 \times 500$ $\mu \mathrm{m}$ mesa stripes were formed. A vertical device geometry was employed. Pd and Ni were used as top and bottom ohmic contact metals to $\mathrm{p}-\mathrm{GaN}$ and $\mathrm{n}$-SiC, respectively. The location of pn junctions in the heterostructures was determined by simultaneous detection of electron beam induced current (EBIC) and back scattered electron (BSE) signals in a scanning electron microscope.

\section{Results}


Edge CL peaks for AIGaN layers with various AIN mole fractions are shown in figure 1. An increase of the AIN mole concentration leads to a "blue" shift of the edge peak position, alloy broadening and a reduction in CL intensity. The dependence of the edge peak energy position on the AIN mole fraction $(x)$ is shown in figure 2. Curve 1 corresponds to linear band gap energy approximation $E(x)=3.4(\mathrm{eV})+2.8(\mathrm{eV}) x$ and curve 2 depicts the approximation: $E(x)=E(0)+a x+b x^{2}$, where $E(0)=3.4 \mathrm{eV}, \mathrm{a}=2.19 \pm 0.16 \mathrm{eV}$, and $\mathrm{b}=0.65 \pm 0.14 \mathrm{eV}$.

BSE and EBIC signal profiles across a p-Al $0.05 \mathrm{Ga}_{0.95} \mathrm{~N} / \mathrm{n}-\mathrm{Al}_{0.03} \mathrm{Ga}_{0.97} \mathrm{~N}$ heterostructure are shown in figure 3 . The minimum in the BSE signal corresponds to the alloy layer in the structure. The CL spectrum (figure 4) has two short wavelength peaks corresponding to carrier recombination in p- and n-AIGaN regions. In the EL spectrum (figure 4), only the n-AlGaN-related peak was observed. The peak position corresponds to carrier recombination in the narrower bandgap n-AIGaN region. In both spectra the edge luminescence from the GaN region $\left(\lambda_{\max } \sim 365 \mathrm{~nm}\right)$ was also observed. The fact that the EL spectrum contains a peak situated at $365 \mathrm{~nm}$ means that holes injected into the $n-A I G a N$ region of the pn junction reach the $n-G a N$ layer and recombine there. It was found that the photon energy for the EL edge peak measured from AIGaN pn junctions follows the same compositional dependence as the CL edge peak does.

A typical EL spectrum taken under dc conditions on a DH having a GaN active layer is shown in figure 5. The edge peak was detected at $365 \mathrm{~nm}$. The full width at half maximum (FWHM) of the edge peak was $86 \mathrm{meV}(300 \mathrm{~K})$. The impurity related emission in the wavelength range from 400 to $450 \mathrm{~nm}$ and the so-called "defect» emission at 550 $\mathrm{nm}$ are also presented in the spectra [2]. As the temperature is increased, the edge emission peak shifts to longer wavelengths, its FWHM increases, and intensity falls off (figure 6). The temperature dependence of the EL edge peak energy position was almost the same as that determined previously for the PL edge peak of GaN layers grown on $\mathrm{SiC}[6]$.

We may conclude that $\mathrm{AIGaN/(Alln)GaN} \mathrm{heterostructures} \mathrm{having} \mathrm{an} \mathrm{edge} \mathrm{EL} \mathrm{peak} \mathrm{at} \mathrm{a} \mathrm{wavelength} \mathrm{corresponding}$ to near band gap recombination in the active region of the structure can be grown on SiC substrates.

\section{Acknowledgments}

The authors thank K. Vassilevski and V. Sizov for mesa fabrication by plasma etching and E. Kalinina and N. Seredova for help in sample preparation. A. Zubrilov and D. Tsvetkov also thank the Russian Foundation of Fundamental Research (contract number 95-02-04148-a) for financial support.

\section{References}

[1] S. Strite, H. Morkoç, J. Vac. Sci. Technol. B 10, 1237-1266 (1992).

[2] AS Zubrilov, DV Tsvetkov, VI Nikolaev, VA Soloviev, VA Dmitriev, Inst. Phys. Conf. Ser. 142, 1003-1006 (1996).

[3] VA Dmitriev, KG Irvine, JA Edmond, et al., Inst. Phys. Conf. Ser. 141, 497-502 (1995).

[4] IP Nikitina, VA Dmitriev, Inst. Phys. Conf. Ser. 141, 431-436 (1995).

[5] KV Vassilevski, VE Sizov, Al Babanin, YuV Melnik, AS Zubrilov, Inst. Phys. Conf. Ser. 142, 1027-1030 (1996).

[6] A. S. Zubrilov, V. I. Nikolaev, D. V. Tsvetkov, V. A. Dmitriev, K. G. Irvine, J. A. Edmond, C. H. Carter, Jr., Appl. Phys. Lett. 67, 533-535 (1995). 


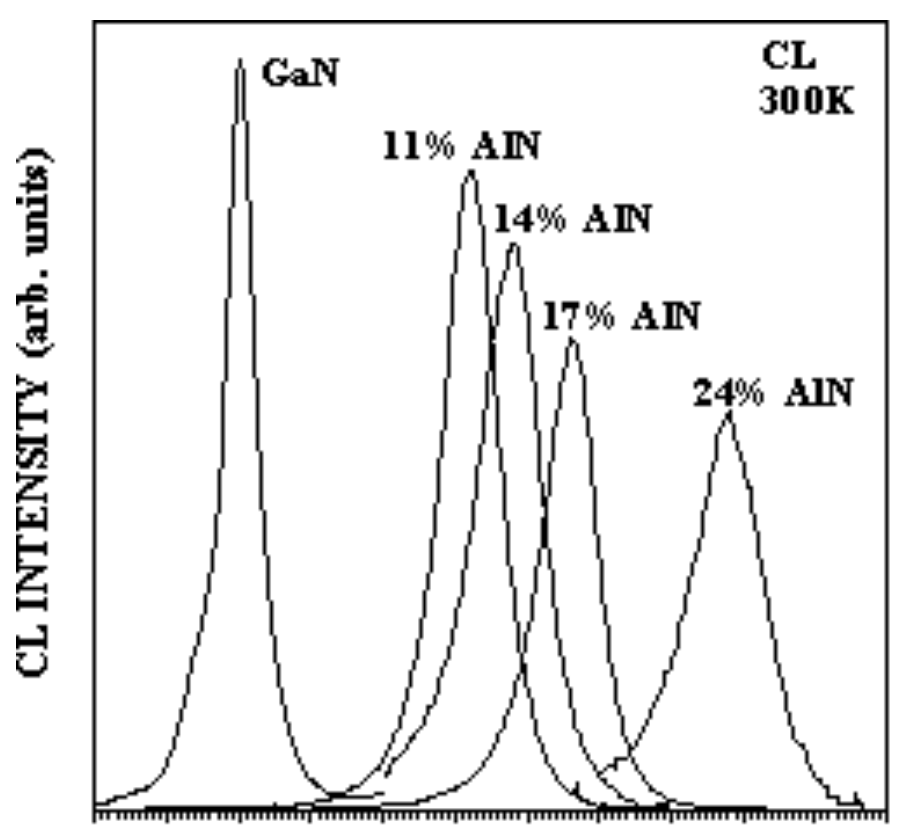

$\begin{array}{llllllllllll}3.2 & 3.3 & 3.4 & 3.5 & 3.6 & 3.7 & 3.8 & 3.9 & 40 & 4.1 & 4.2 & 4.3\end{array}$ PHOT ON ENERGY (eV)

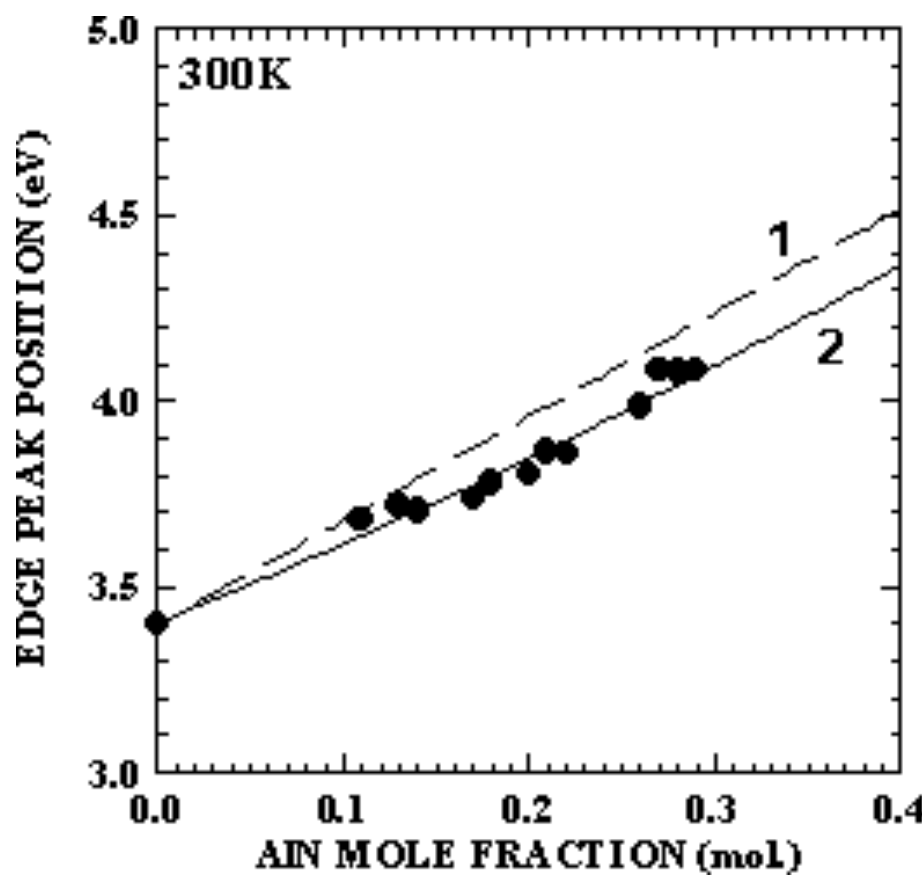

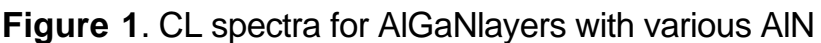
concentrations

Figure 2. Dependence of the $C L$ edge peak position on AIGaN composition 

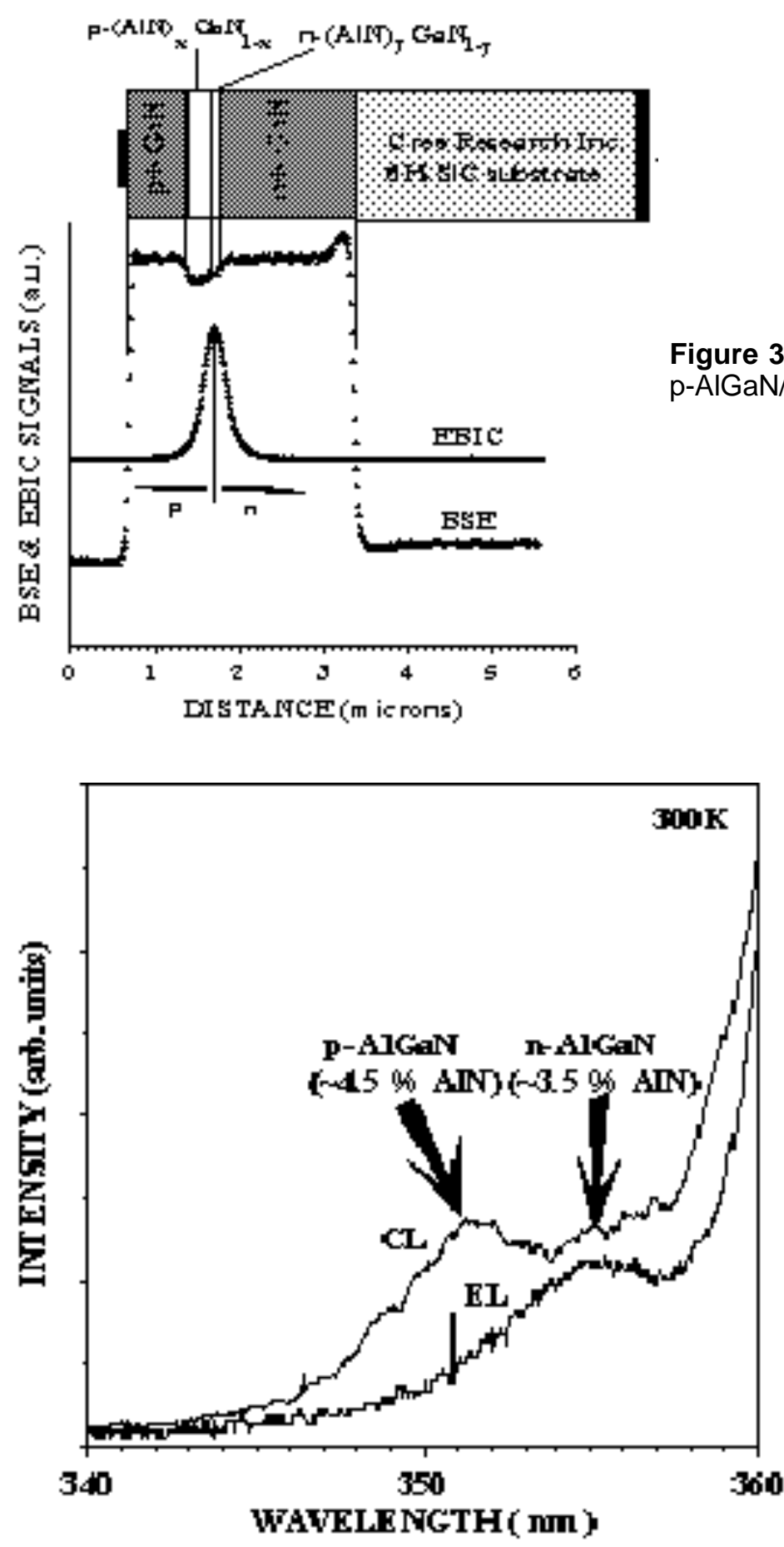

Figure 3. EBIC and BSE signal profiles across the $\mathrm{p}-\mathrm{AlGaN} / \mathrm{n}-\mathrm{AlGaN}$ heterostructure
Figure 4. EL and CL spectra for the structure shown in figure 3 

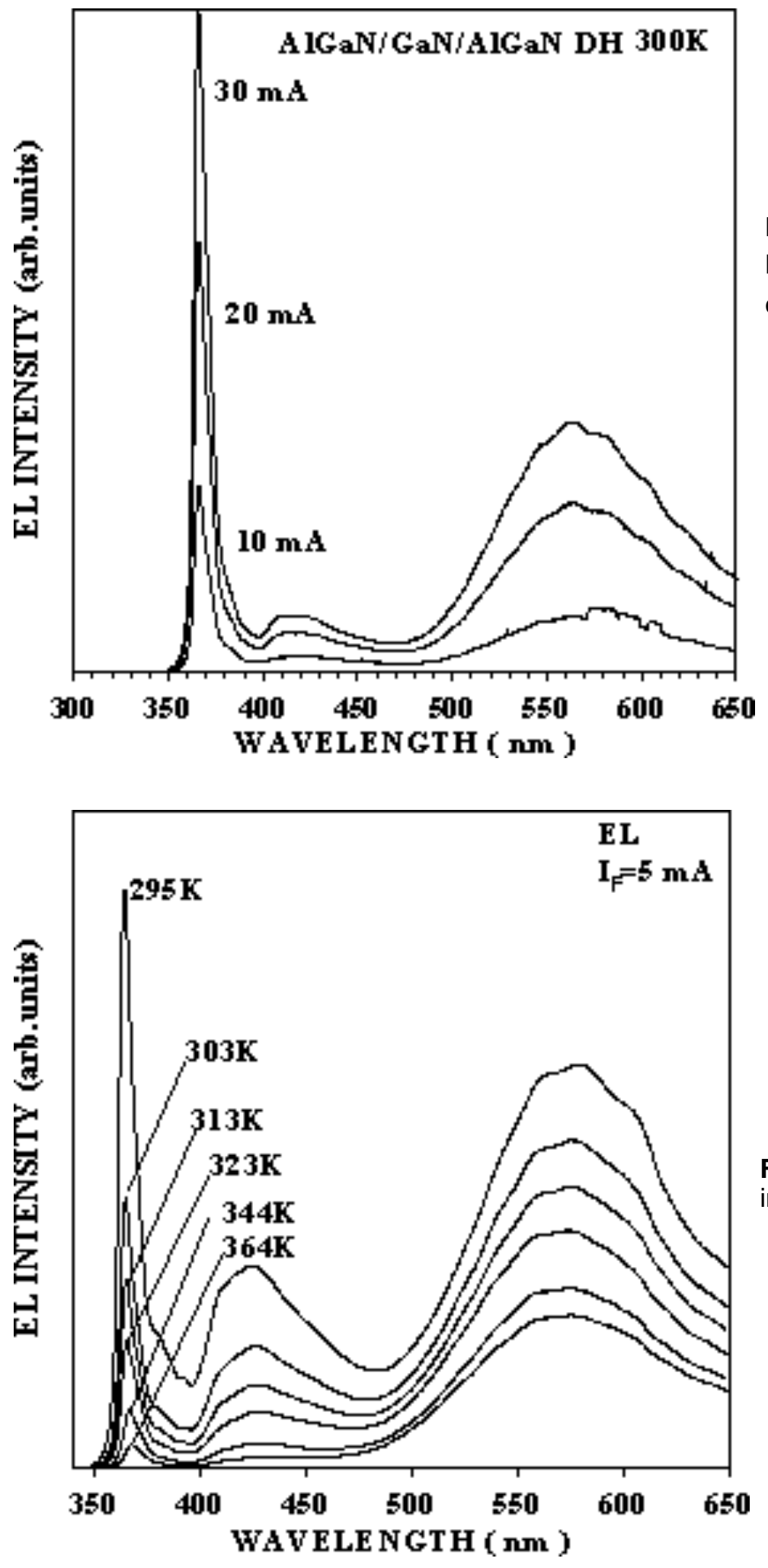

Figure 5. EL spectra of a p-Al $0.08 \mathrm{Ga}_{0.92}$ $\mathrm{N} / \mathrm{GaN} / \mathrm{n}-\mathrm{Al}_{0.02} \mathrm{Ga}_{0.98} \mathrm{~N} \mathrm{DH}$ at various forward currents
Figure 6. EL spectra of the $\mathrm{DH}$ shown in figure 5 in the temperature range from $300-360 \mathrm{~K}$

(C) 1996-1997 The Materials Research Society

\begin{tabular}{|l|l|l|l|l|}
\hline $\mathrm{M}$ & $\mathrm{R}$ & $\mathrm{S}$ & Internet Journal of & Nitride Semiconductor Research \\
\hline
\end{tabular}

